\title{
REFLECTIVE OBSERVATIONS ON THE DESIGN AND STUDIO ART PROGRAMME AT A UNIVERSITY OF TECHNOLOGY
}

\author{
Lebogang Nthejane \\ Department of Design and Studio Art, Central University of Technology Free State (South Africa)
}

\begin{abstract}
The Central University of Technology (CUT) in South Africa compels that all programmes without a Mathematics module to offer Numeracy to first-year students. Initially, the Department of Mathematical and Physical Sciences at CUT was requested to facilitate this module from 2014 within the first semester. However, Numeracy was offered in a general manner without considering the applicability to the Design and Studio Art programme. The aim of this study was to revise the current curriculum and modify it to be applicable to the Design and Studio Art programme. Thus, the objectives of this study were firstly, to identify the gap in the current curriculum, which related to mathematical concepts within the Numeracy module which seemed to be not applicable to this programme. Secondly, to identify the mathematical concepts within the Numeracy module that could possibly be applicable to this Programme and modify them, accordingly. These concepts were identified as geometry, ratios and proportions, scale drawings, grid system, units and conversions. The final objective of this study related to the teaching of these concepts into the programme. The purpose of this paper report on the reflective observations on the revision and modification of the curriculum, more specifically on the application of these concepts in the Drawing module of the Design and Studio Art programme. A qualitative research approach was employed through reflective observations by the lecturer in the drawing lesson of 38 students who were enrolled on this programme. An analysis was further done on students' abilities to apply mathematical concepts in their drawing project and what they have learnt in the Numeracy module. Findings revealed students' abilities to apply mathematical concepts with ease- this after the lecturer explained the relations amongst these concepts to drawing. It appeared as though this intervention benefited mostly the students who were struggling with drawing. A key recommendation is that the application of the stated mathematical concepts be practiced in other modules within the Design and Studio Art programme at CUT.
\end{abstract}

Keywords: Mathematics, drawing, geometry, ratio and proportion.

\section{Introduction}

A question has been raised often if there is a relationship between art and Mathematics. It is evident through literature that a relationship does exist between Art and Mathematics. From ancient history of the Egyptian murals, the use of plane geometry is evident, as well as on the American folk quilts. During the European Renaissance, projective geometry is evident on the works of Durer and da Vinci (Bickley-Green, 1995). According to (Hickman \& Huckstep 2003), the link between art and mathematics has been evident centuries ago on the Euclidean geometry and is recently evident in cross-curricular in schools. However, a lot of art students and art educators do not recognise the relationship between art and Mathematics. In her study (Bickley-Green, 1995) stated that students and preservice teachers could not identify any mathematical concepts in the art curriculum. Teachers only saw themselves as artists and not mathematicians, hence they did not do well in mathematics, and students claimed that they have never been asked to calculate anything in art.

According to (Lusardi, 2012), to succeed in today's economic environment, Numeracy and financial literacy are recently deemed to be crucial lifetime skills. Since 2014 the Central University introduced the Numeracy module to the 1st year curriculum of all the programmes that do not offer mathematics, as being numerate is one of the university's graduate attributes. However, the Numeracy module was offered as an individual discipline, and therefore seemed irrelevant to the Design and Studio Art students. Therefore, based on the evident relationship between mathematics and art, there was a need to revise the Numeracy module curriculum to be applicable to Design and Studio Art. The objectives for Numeracy were for students to be able to apply these skills in real-life situations, hence it was necessary 
for Design and Studio Art students to be able to apply numeracy skills in their daily life of art making. These objectives led to a curriculum integration approach of Numeracy module and Drawing module which is one of the Design and Studio Art modules. Society is changing, the art world changes too as well as our communication modes changes, due to these changes there is a renewed interest in an integrated curriculum approach in art education. (Parsons 2004) is of the opinion that curriculum integration could enhance the teaching of art.

Drawing is a fundamental aspect of art, and it involves the ability to see and interpret what you see into a two-dimensional plane (Bulduk, 2010). When looking at an object to be drawn, one must ask themselves what is it that they see and not just merely see a human being, but rather see line, shape, form and so on (Barber 2003). This way of seeing is what brings mathematics and drawing together, both disciplines involve geometry. The "Vitruvian Man" one of Leonardo da Vinci's famous drawings demonstrates the old ways of using geometry to achieve correct human figure proportions. The Vitruvian man concept suggested that a circle and a square which were known to be perfect geometric figures, would frame a perfectly proportional man with his extended arms and legs (Mello 2010). The Drawing process is mathematical itself.

\section{Aim of the study}

The aim of this qualitative study is to revise and modify the Numeracy curriculum to make it applicable to Design and studio Art and observe the ability of students to apply the mathematical concepts in the Drawing module of the Design and Studio Art programme.

\section{Methodology}

A qualitative method was employed for the purpose of this study. Data was collected through a reflective observation by the lecturer during two drawing lessons in the department of Design and Studio Art at the Central University of Technology, Free State. According to (Dewey 1997), reflection is about searching for new evidence to support one's suggestions. This study aims at developing a strategy to assist students to develop their ability to apply mathematical concepts in drawing through an integration of both the Numeracy module and Drawing curriculum. The Participants were 38 first year students enrolled for the Drawing Module and Numeracy Module. Participants were informed that their classroom activities will be observed and that the observations will be used for research purposes in order to enhance teaching and learning. Only a few participants had some background in art and majority of the participants did not have any prior knowledge in art as it was not a requirement to enrol for the Design and Studio Art programme. Students were taught the revised and modified Numeracy module and thereafter given two tasks in the drawing Module to test their ability to apply mathematical concepts in their drawings. For the purpose of this study, only four mathematical concepts were observed, namely geometry, proportions, scale drawing and grid system. Firstly, students were instructed to apply geometry and proportions in one project and use scale drawings and the grid system in the other project, without the mention of Numeracy. Subsequently, an observation was done through a written report. Secondly, a demonstration of the relationship of these concepts between Numeracy and Drawing was given to the students and thereafter expected to draw accordingly. More focus on the demonstration was given to the students who were struggling with drawing. Another observation was done while students were drawing after the demonstration. Thereafter a reflection was done on these written observations to determine the ability of students to apply proportions and the grid system in their drawing projects.

\section{Presentation and analysis of results}

The presentation is done according to the mathematical concepts that were drawn from the analysis of the reflective observation data. Four of the mathematical concepts identified in the Numeracy module were taught to students and therefore students were instructed to apply these concepts in their drawing projects. Findings of the reflective observations will be presented briefly in two sections.

\subsection{Application of geometry, ratios, and proportions in drawing}

This section is the presentation of how the students performed in the drawing class in an attempt to apply geometry, ratios and proportions in their drawing projects. In drawing, proportions are very challenging and need an understanding of measurement. When drawing for accuracy, it is important to keep the same proportion in the drawing as on the actual object. In Numeracy the students learn that proportion means rations are equal whether scaled up or down. In drawing proportions is how objects relate to each 
other in size. These approaches are similar although they appear to be different. The difference is numbers for Numeracy and size for drawing, of which size can be seen as a number too.

Students were given a life human figure drawing project to exercise the use of geometry and proportions. In their first attempt they could not break down the figure into geometric forms. Regarding first attempt of proportions, students were able to measure the life human figure with their pencils, however the majority were not able to translate the measurements onto paper. Some students did not understand that where they hold the pencil to measure the head is actually a measuring unit, they did not hold the pencil at the same place, making the measuring unit to be unstable and therefore miscalculating the proportions of the figure. On the other hand, some students were able to keep the measuring unit stable, however were unable to scale up the proportions on a big paper. They would draw a tiny figure on less than a quarter of the paper. A second attempt was given to the students after showing them geometric forms they learnt from Numeracy and how they could be used to simplify a complex organic figure. On the second attempt, students showed an improvement in their measuring skills and were able to recognise geometric forms on the structure of the human being. Those students who could only draw a stick man were able to use geometric forms to give their stick man some form.

\subsection{Application of scale drawing and grid system in drawing}

The performance of students on the application of scale drawing and grid system in their drawing projects will be presented in this section. In Numeracy scale drawing entails enlarging or reducing a real object size to a bigger or smaller scale on paper. The grid system is also used in scale drawing. These concepts are also evident in drawing; however, students struggle with scale calculations as they dislike mathematics. There has to be a mind shift to get students to measure.

Students were instructed to draw their self-portraits from a small photo to a bigger paper using the grid system. Although they were given instructions on how to draw a grid in order to achieve the correct proportions on a bigger scale, many students did not draw the grids properly. The grids were either not equal or they were skew. Some students struggled to scale up the grids from the photo to the drawing. Due to these challenges encountered by the students, examples were given to them from what they learnt in the Numeracy module and thereafter they were advised to use the same calculation method used in the Numeracy module. Students faced another challenge of following the grids to draw on the bigger paper and this led to distortion or proportional disorders of the portrait. Students were thereafter encouraged to number the grids on the $\mathrm{x}$-axis and the $\mathrm{y}$-axis and place the facial features according to the grid reference method they used in the Numeracy module. After this intervention, students were able to conquer some of the challenges they faced as well as improve their portrait drawing skill.

\section{Discussion}

Findings from the reflective observation on the students' ability to apply mathematical concepts, indicate that knowledge alone is not significant, alternatively the ability to apply knowledge contributes significantly in learning. According to (Dicker 1972) Dewey states that "...knowing is not the act of an outside spectator but of a participator...". He further explains that knowledge is a result of action taken. Results show that students were able to understand the link between maths and art within the Numeracy module, however, they had challenges to apply the knowledge in a real life situation of a drawing project. Subsequently, the students were able to apply the mathematical concepts through the integration of both the Numeracy and Drawing module curriculums. This indicates that the integration of the two disciplines contributed to the development of the students' ability to apply mathematical concepts in their drawing projects. Findings also indicate that the traditional way of teaching drawing with the use of structural lines was a bit challenging to the students who had no background in art. However, the application of geometry, proportions, scale drawings and grid system as a way of learning to draw, seemed to be assisting the students in the development of their drawing skills. This was more evident on the students who were struggling to draw. This suggestion is supported by (Christenson 2017) that using mathematics to teach art is crucial and that it provides supportive ways for students to be able to solve creative problems in art.

It can be concluded that modifying the Numeracy module to be applicable to Design and Studio Art assisted the students to recognize the connection between mathematics and art. The relationship between these two separate disciples has been evident The integration of the curriculum of Numeracy and Drawing module curriculum brought an interesting way of learning that enabled students to develop their ability to apply mathematical concepts in their drawing projects as well as improve their drawing skills. These results show that mathematics should not be separated from art as they are intertwined in their processes. 


\section{Conclusion}

The findings of this study revealed that mathematics is relevant to art and that applying mathematical concepts from the Numeracy module into the drawing module assisted the students to understand the relationship better and therefore improving their drawing skills. Students who already had adequate drawing skills perfected their skills while those who did not have any drawing background were able to develop the drawing skill adequately.

\section{References}

Barber, B. (2003). Advanced Drawing Skills: A Course in Artistic Excellence. Barnes \& Noble.

Bickley-Green, (1995). Math and Art Curriculum Integration: A Post-Modem Foundation Cynthia. A Journal of Issues and Research National Art Education Association, 37 (1), 6-18.

Bulduk, B. (2010). The relationship of the traditional drawing education with technology and graphic design. Procedia - Social and Behavioral Sciences, 2(2), 2019-2023

Christonsen, M. (2017). 3 Ways Using Math Can Improve Students' Drawings. May 24, 2021, https://theartofeducation.edu/2017/04/12/april-key-ways-draw-using-math/

Dewey, J. (1997). How we think (Dover. Ed.). Boston: D, C, Heath \& Co

Dicker, G. (1972). John Dewey on the Object of Knowledge. Transactions of the Charles S. Peirce Society, 8(3), 152-166

Hickman, R. Huckstep, P. (2003). Art and Mathematics in Education. The Journal of Aesthetic Education 37(1): $1-12$

Lusardi, A. (2012). Numeracy, Financial Literacy, and Financial Decision Making. Numeracy: Advancing Education in Quantitative Literacy 5(1), Art2

Mello, HA. 2010. Geometry in Art. February 2, 2018, http://www.hamello.com/PDF/livro_en.pdf

Parsons, M. (2004). Art and Integrated Curriculum. Eisner, EW. Day, MD. Handbook of Research and Policy in Art Education (20). New York: Routledge 